69. Cambridge:

sward a theoret51-208.

or development ierver, 15,225

What is an apanning, 5, 316-
Journal of Human Behavior in the Social Environment, 20:909-923, 2010

Copyright $\odot$ Taylor \& Francis Group, LLC

ISSN: 1091-1359 print/1540-3556 online

DOI: $10.1080 / 10911359.2010 .494975$

\title{
Conceptual Tools for Research on Race and Social Problems: An Overview of Dynamic Theory and Model Development
}

\author{
VON E. NEBBITT \\ Jane Addams College of Social Work, University of Illinois at Cbicago, Cbicago, Illinois, USA \\ SABRINA W. TYUSE \\ School of Social Work, Saint Louis University, St.Louis, Missouri, USA \\ MICHAEL G. VAUGHN \\ Scbool of Social Work, Saint Louis University, St. Louis, Missouri, USA \\ BRIAN E. PERRON \\ School of Social Work, University of Michigan, Ann Arbor, Michigan, USA

\begin{abstract}
Although interpersonal, group processes and inter-group relationships are dynamic phenomena, researchers bave studied these phenomena in a static manner. This article provides an overview of system dynamic modeling to bring greater attention to the importance of dynamic theoretical formulations and presents important concepts and tools that can facilitate movement in this direction. Important concepts for theory development are delineated, and various reasons why the field has a penchant for static theoretical formulations are explored. A set of tools and concepts from system dynamics is presented to guide dynamic thinking and future theory building.
\end{abstract}

KEYWORDS System dynamics, dynamic modeling, race and social problems, inter-group relations

Researchers studying forms of inter-group processes (and social psychological phenomena in general) are interested in explaining or predicting "dynamic," or time-varying, phenomena. Substantive topics such as conflict (e.g., Dovidio, Gaertner, Esses, \& Brewer, 2003), ostracism and aggression (e.g., Williams \& Warburton, 2004), social identity development (e.g., Hogg, 2006), and prejudice (e.g., Tropp, 2007) are all in large measure dynamic-dependent

Address correspondence to Michael G. Vaughn, School of Social Work, Saint Louis University, 3550 Lindell Boulevard, St. Louis, MO 63103, USA. E-mail: mvaughn9@slu.edu 
relationships. Unfortunately, the vast majority of theories and models in the literature are "static" formulations of the phenomena: That is, they focus on stationary behavior and do not account for change over time. The majority of these formulations are offered in the form of comparative statistics (see Hanneman, Collins, \& Mordt, 1995; e.g., cohesion produces pressures to conform, and uncertainty leads to susceptibility to social influences, largely ignoring the periods of time in which they unfold). These static models have proven useful for forecasting and predicting certain events, but they cannot explain the process of change.

Dynamic formulations of phenomena, conversely, focus explicitly on both time and change. The formulations rely on causal relationships, as opposed to correlational relationships, which are situated in feedback relationships. Time is also viewed as a continuous process; so cross-sectional research methodologies are not typically used in theory development and testing. As dynamic variables in feedback relationships can produce unexpected patterns of behavior, dynamic theories of the process are not suitable for prediction. Rather, their utility is in their ability to explain dynamic behavior.

Dynamic theories are not necessarily superior to static theories. Both types serve an important and unique purpose in understanding human interactions, and they should be judged according to their purpose. At the same time, it is important to recognize that fields investigating various forms of human interactions in general evince a lack of dynamic theories relative to static ones. Given the central importance of inter-group relations in the study of race and social problems, this article seeks to bring greater attention to the importance of dynamic theoretical formulations and presents important concepts and tools that can facilitate movement in this direction. To this end, this study first works to clarify important concepts of theory development and explores various reasons why the field has a penchant for static theoretical formulations. Then, a set of tools and concepts from system dynamics is presented to guide dynamic thinking and theory building.

\section{AN OVERVIEW OF MODELS AND THEORIES}

The terms theory and model lack uniformity among scientists, in particular social scientists (see Rudner, 1966). To help bring some clarity, this article adopts Rudner's definition of theory,' which is "a systematically related set of statements, including some lawlike generalizations, that is empirically testable" (p. 10). As scientists well know, theories provide an organized account of the world to explain or predict. Theory building is a demanding enterprise, and only a few theories ever become "fully formalized." A fully formalized theory is one that contains a completely articulated deductive system. Theories of interpersonal relationships are only partially formalized: That is, they contain definitions and some axioms but are typically hazy and 
incomplete in logical structure. Thus, the theories are left open to multiple interpretations. This is not necessarily a criticism, as it is not practical or even desirable to achieve full formalization (see Rudner).

Because these theories are only partially formalized, it is important to consider that the theories are not tested directly per se. Rather, the theories are interpreted and represented in the form of models, namely statistical models. It is self-evident that models are a necessary part of the theorybuilding process, as they provide a means for both analytic and empirical testing. Thus, as we work toward explaining dynamic processes, it is important that our theories are dynamic and that our models are isomorphic with or at least have good correspondence with the theory.

As previously stated, dynamic theories are not necessarily better than static ones: They serve unique purposes. Given the field's interest in dynamics, an objective critique of the field might very well raise the question, Why are most theories and models that belong to this field static? There are at least three possible explanations. First, cognitive and language limitations are major barriers to understanding and describing dynamic behavior. Our minds view the world as linear and sequential processes. Thus, it is difficult to identify and communicate the complex feedback relationships that give rise to dynamic behavior. Second, it seems as though the widely accepted use of general linear models reinforces the formulation of static models. These are part of the core statistical tools of social science and psychological research and, perhaps more important, are widely available in the form of commonly used software packages. They tend to frame problems in a manner that is suitable to these models and draw boundaries around research questions. If differential equations were part of the mainstream of social science and psychological research, the study of dynamic processes might have more recognition. So, though we may dream of building a castle made of chiseled stone, we probably have to settle for a wood-framed bungalow. Perhaps the bungalow could be retrofitted with a brick façade but is still a bungalow. In other words, we can only push our current methodology so far in the attempt to explain dynamic processes.

The third reason is that studying change processes requires significant resources to conduct longitudinal or time series studies. Unfortunately, not all good research ideas are appropriately funded. Cross-sectional designs are often easier and cheaper to conduct, but those often exclude the opportunity to look carefully at dynamic processes.

The purpose of identifying these barriers is not to create an overly pessimistic attitude toward the field. In fact, these barriers might be more aptly described as opportunities, given advances in technologies and theory that have not been clearly recognized by this field. For example, advances in computer technologies, most notably in the area of computer simulation, provide a way for facilitating the studying of dynamic processes. System dynamics computer simulation programs such as Vensim (Ventana 
Systems, 2004) and Stella (High Performance Systems, 2004) are relatively user-friendly, economical, and versatile and are appropriate for both budding and advanced social scientists. A variety of tools and concepts from system theoretical approaches can also help researchers think dynamically. Although these developments are far from perfect, they do offer optimism for the future of research on dynamic processes.

\section{Tools for Dynamic Thinking}

Broadly defined, a system is any set of interrelated elements that influence each other over time (Roberts, Andersen, Deal, Garet, \& Shaffer, 1983; Senge, Kleiner, Roberts, Ross, \& Smith, 1994). Systems are ubiquitous and exist in many forms and sizes. Examples of systems include, but are not limited to, a cell, the solar system, the human body, a community, a hospital, a football team, war, families, a pond, classrooms, and so on. Interpersonal phenomena can also be conceptualized as systems. People interact with one another in a manner that gives rise to dynamic processes, such as pressures to conform, decision-making biases, attitudes and attitude changes, power, influence, and the like. These interactions are often non-linear and quite complex (Thelen \& Smith, 1998). It is important to recognize that these individual actors operate within successive levels of context and constraint such as neurobiological, political-economic, and cultural processes (see Matsumoto, 2007; Peck, 2007; Vaughn, 2007).

The study of systems is guided by a variety of theoretical approaches (e.g., general systems theory, cybernetics, chaos theory, gestalt theory, and system dynamics) that fall under the general rubric called systems theory. They all share the idea that the behavior of systems is generated by its underlying "structure" or the pattern of interrelationships that comprise the system. And an understanding of system structures always presupposes explanations of the dynamic process. Although we acknowledge the value of newer conceptualizations such as complexity theory (Walby, 2007) or emergentism (Elder-Vass, 2007), this study is largely informed by the system dynamics approach, which was developed by Jay Wright Forrester in the 1950 s at the Massachusetts Institute of Technology.

\section{Systems Thinking Tools}

"Systems thinking" is the practice of uncovering the system's structure by applying various analytic strategies, tools, and principles to arrive at valid explanations of dynamic processes. The field of system dynamics is replete with such tools. Two tools that are germane to theory development in interpersonal relations are reviewed further. These include behavior over time graphs and causal loop diagrams (CLDs). A description of other tools can be found in Senge et al. (1994) and Ford (1999). 


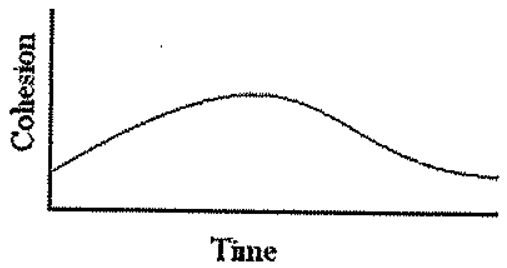

FIGURE 1 Behavior over time graph.

\section{BEHAVIOR OVER TIME GRAPHS}

A behavior over time graph (BOTG) is a graphical depiction of changes that a variable exhibits over time. Figure 1 is an example of a BOTG representing an oscillatory pattern of change for the variable called cohesion. The $\mathrm{X}$-axis signifies time, and the Y-axis signifies quantitative values.

Note that the exact values are not specified in this graph, as it is more important to capture the qualitative changes in behavior (i.e., the shape of the change) rather than the precise values associated with the change. Oftentimes, specifying exact variables will result in a graph with many shortterm fluctuations, which are largely attributed to noise in the data. The real underlying process of change is more likely a smooth process. Theoretically, there are an infinite number of different patterns of change that can be represented in BOTGs.

There are a variety of ways that BOTGs can be used to encourage dynamic thinking. Foremost, they can help specify a "time horizon" for the theory, thus bringing the element of time to the forefront of the theory building process. More specifically, dynamic theories should be developed around a suitable temporal interval in which the phenomenon of interest is occurring. A researcher may be interested in the dynamics of conformity on college campuses. A dynamic theory of conformity that explains changes over a 1-year process will differ significantly from a dynamic theory that explains change over a 25 -year period. BOTGs are also useful for uncovering the system structure that gives rise to dynamic behavior. The BOTG of group cohesion (see Figure 1) denotes a rise in cohesion that is followed by a decline as it tends toward a state of equilibrium. This graph can also be partitioned into general phases of behavior that represent when certain types of feedback loops are dominating the system behavior (Figure 2). More attention will be paid to the concept of feedback structures later in this article, which will bring further clarity to this point.

\section{CAUSAL LOOP DIAGRAMS}

Another important tool that can facilitate the development of dynamic theories is the causal loop diagram. A CLD is a graphical depiction of a system that uses arrows and other symbols to represent the system's underlying 


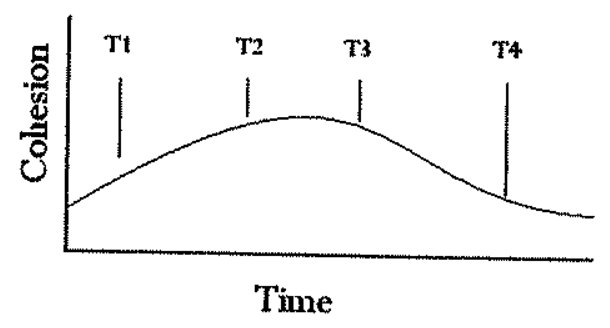

FIGURE 2 Behavior over time graph with phases of behavior.

causal processes. An example of a CLD is presented in Figure 3. The benefits of using CLDs will be discussed first, then the graphical notation will be reviewed in greater detail.

There are at least three benefits of using CLDs for theory development. The first benefit is their ability to serve as an analytic tool for helping to sort out and think through complex sets of causal relationships. Considering that theory development is an iterative process, CLDs provide a means for quickly (albeit thoughtfully!) proposing and testing the logical consistency of causal relationships. Gaps and holes in theoretical formulations can also be easily identified. Thus, they can nicely complement the narrative process, which can often be stultifying.

The second benefit of CLDs is their capability of communicating theoretical formulations accurately and efficiently. The graphical notation of CLDs is largely standardized, so relationships can be unambiguously communicated,

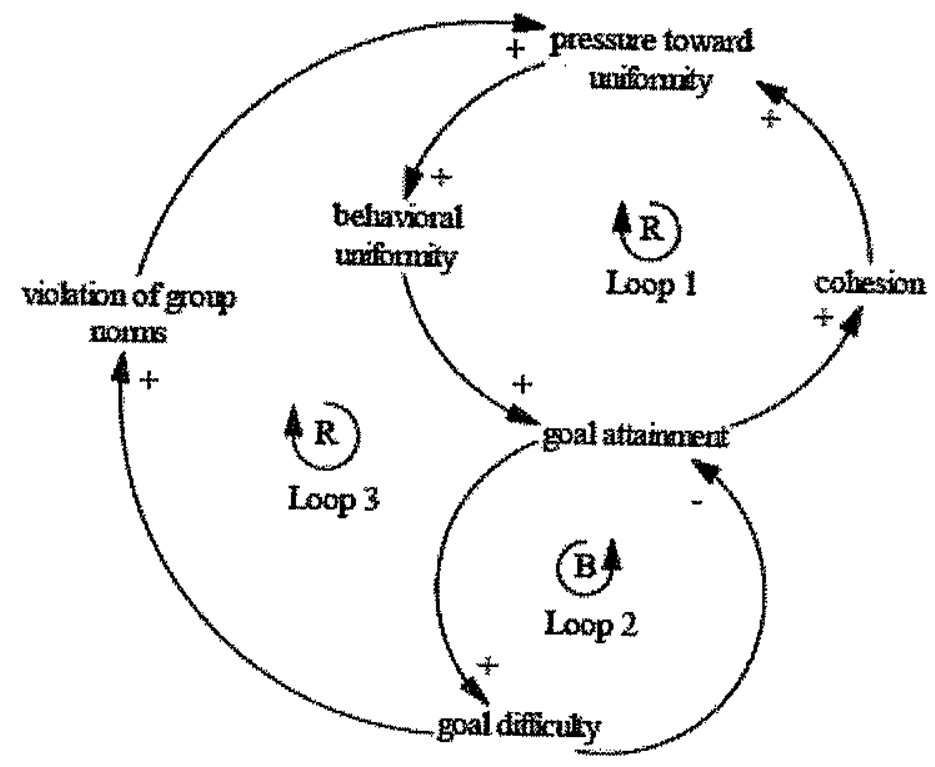

FIGURE 3 Causal loop diagram example. 
Ienefits will be

pment. jing to idering ans for istency an also irocess,

heoretCLDs is licated,

even in the absence of verbal formulations. This benefit can allow the theoretician to invest more efforts on defining concepts and terms in the theory and less time on the verbal explication of complex relationships.

The third advantage of CLDs is that they can be converted into stockflow diagrams. Stock-flow diagrams are the basis on which computer simulations of dynamic theories are built, which provides the means for empirical testing. Many argue that computer simulations are an essential means for testing dynamic theory (Homer \& Oliva, 2001), and they are gaining increased attention in the social sciences. However, this methodology can only be as strong as the theories that are being tested. CLDs serve as a point of departure by promoting the development of dynamic theory, which can then be integrated with computer simulations.

\section{Dynamic Concepts}

Systems thinking tools are necessary but an insufficient means for building accurate representations of systems and explaining system behavior. This section outlines some of the concepts that are necessary for developing dynamic theories and models.

\section{FeEDBACK}

Static theories are typically formulated in terms of X-Y causal relationships. Consider the hypothetical formulation depicted in Figure 4, wherein pressures to conform is a partial mediator between group cohesion and goal attainment.

This formulation can be used to predict goal attainment with some degree of accuracy, but the explained variance of the model (i.e., $R^{2}$ ) does not explain how the variables generate a change in goal attainment over time. It also assumes that the dependent variable, goal attainment, has no influence on other elements of the system.

From a systems perspective, causal relationships such as the ones described earlier never exist in isolation. Rather, they are arranged in circles of causality, whereby every element is both a cause and an effect (Forrester, 1968; Roberts et al., 1983; Senge et al., 1994). This type of relationship is

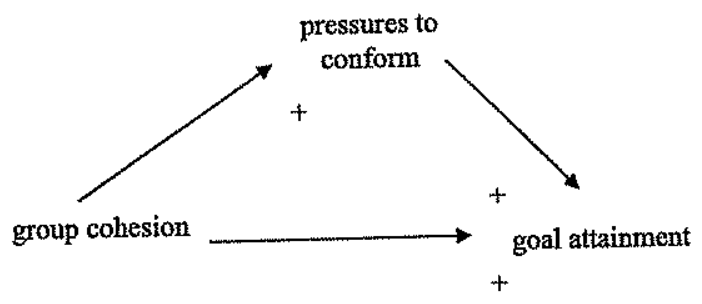

FIGURE 4 Static formulation example. 


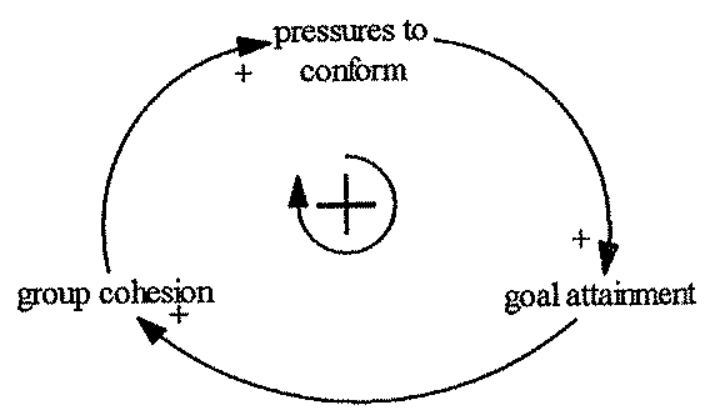

FIGURE 5 Dynamic formulation example.

called feedback, and it occurs whenever the result of an action or change returns to the system to influence the original source of behavior. Having an understanding of feedback relationships is essential because they constitute the structure of the system, which generates the behavior of the system (Forrester). Returning to the prior example, a feedback loop connecting these three variables can be postulated. This feedback loop is presented as a CLD in Figure 5.

The arrows indicate the causal relationships (not correlational relationships), the plus sign at the arrowheads indicate that each causal relationship is positive, and the plus sign in the middle of the loop indicates the loop's "polarity," Loop polarity refers to whether the loop exhibits positive or negative feedback. In this example, the loop is positive. The differences between positive and negative feedback are discussed further on.

\section{POSITIVE FEEDBACK}

A positive feedback relationship produces accelerated growth or decay in the system as the change process builds upon itself. The prior example shows a positive feedback process whereby group cohesion causes an increase in pressures to conform. The conformity leads to the attainment of goals, in turn increasing group cohesion. Though this is a positive feedback relationship, it is important to recognize that the reverse can also occur, wherein a low level of group cohesion erodes pressures to conform and inhibits the attainment of the goals. This results in a vicious cycle.

The polarity of feedback loops can be discerned by counting the number of negative causal relations in the loop. When there are no negative causal. relations or an even number of causal relations, the polarity of the loop is negative. This means that the direction of causality when traversing the loop does not change directions. Figure 5 has zero negative causal relationships, so the polarity of that loop is positive.

BOTGs can help identify when positive feedback loops are dominating the behavior of the system. In Figure 6, time periods one and three show growth and decay, respectively. 
or change

Having an constitute re system ting these as a CLD 1 relationlationship he loop's ositive or ifferences

say in the le shows crease in is, in turn onship, it low level tainment

: number re causal 2 loop is the loop onships, minating ee show

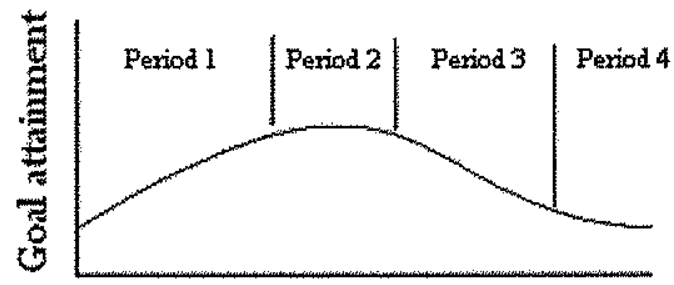

Time

FIGURE 6 Behavior over time graph by loop dominance.

These processes indicate that a positive relationship is dominating the system. As most systems are composed of many feedback relationships, it is unlikely that a single feedback loop will account for both phases of growth and decay. Further theoretical and empirical work is necessary to identify the full set of feedback relationships.

\section{NEGATIVE FEEDBACK}

Negative feedback relationships exhibit goal-seeking behavior: That is, they seek system stability or "equilibrium." Negative feedback relationships underscore a fundamental principle of system behavior-that there are limits to growth. No system can exhibit unrestricted infinite growth patterns. Negative feedback relationships slow the growth or delay the process. A negative feedback loop was added to the group cohesion model (Figure 7) to show how the growth process may be slowed. More specifically, it shows that the attainment of goals leads to an increased level of goal difficulty. As the level of difficulty increases, the attainment of goals decreases. This process unfolds over time, seeking a point of equilibrium.

As previously stated, the polarity of the loop can be determined by counting the number of negative relationships in the loop. Negative feedback loops have an odd number of negative relationships. This simple feedback

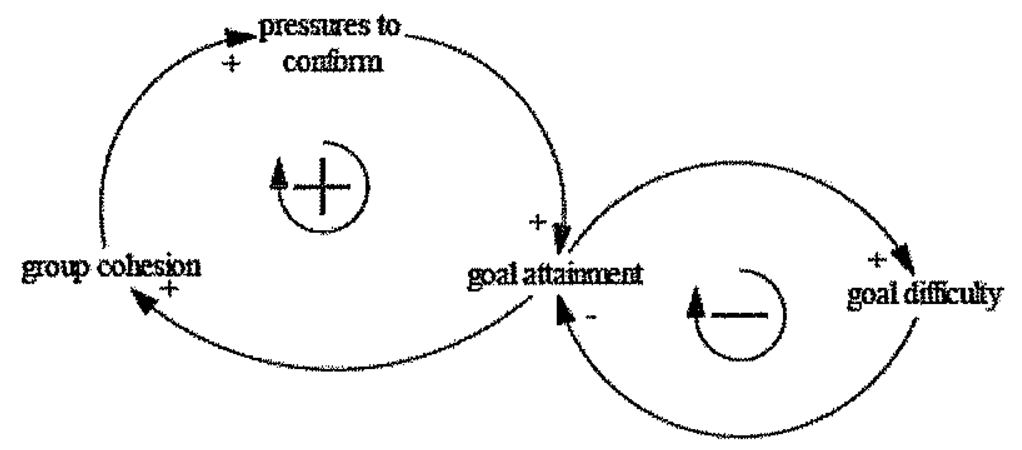

FXGURE 7 Positive and negative feedback. 
loop has only one negative relationship, so its polarity is negative. Another way to determine whether the feedback loop is negative is to select a variable in the system, noting its direction of influence on the next variable. If it changes direction after fully traversing the loop, its polarity is negative.

BOTGs are useful for determining when negative feedback processes are dominating the behavior of the system. Returning to Figure 6 , negative feedback processes can be identified in time periods two and four, as they are showing a deceleration in the change process or system stability.

\section{Delays}

Kelly and McGrath (1988) state that "temporal relations are at the very heart of our causal inferences" (p. 17). Thus, for theories and models to accord with real systems, it is important that the temporal intervals or "time delays" are clearly and accurately specified. It is often the case with dynamic systems that the time delays across relationships are not uniform. That is, some effects may immediately precede the cause, whereas other effects may be delayed by a longer period of time-a few minutes, hours, days, weeks, or even years. It is also important to consider other influences that may be occurring within a system during a particular time delay. As the length of time delays increases, other variables can affect the change process, which makes specification extremely important.

Time delays can be denoted in CLDs by using a double line to bisect relationships wherein the cause-effect relationship is not considered immediate. Figure 8 indicates that a change in the goal difficulty has an immediate effect on goal attainment. It also shows that the attainment of goals has a delayed effect on the goal difficulty. This is a common occurrence in information feedback processes, as it takes time for people to perceive changes in the system and respond accordingly.

Although CLDs can denote the presence of time delay, they are unable to communicate the specific interval and wholly incapable of explicating the

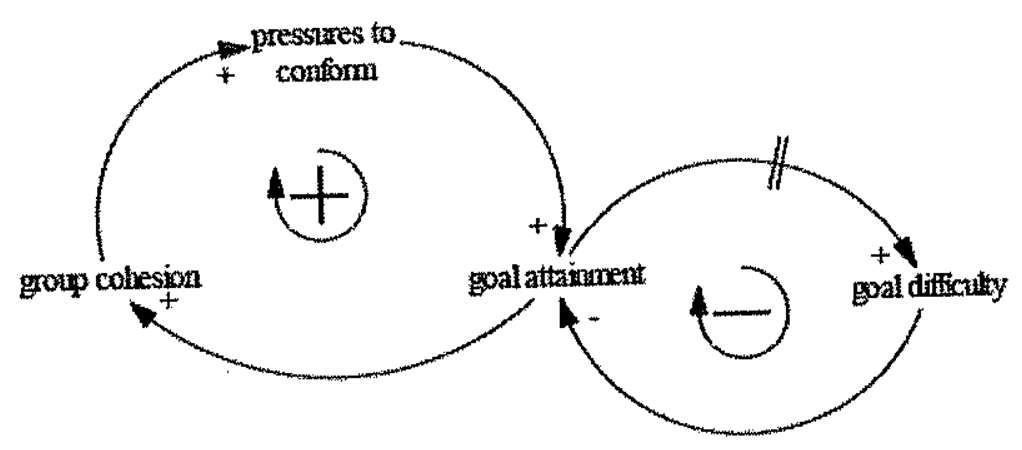

FIGURE 8 Dynamic model with time delay. 
$\therefore$ Another a variable able. If it ative.

processes negative $r$, as they ity.

'ery heart cord with lays" are tems that fects may yed by a years. It : within a ncreases, ification

le to binsidered 7 has an iment of currence perceive 2 unable ting the

impact they produce on the overall system. This is an important limitation and clearly indicates that CLDs should only supplement the development of dynamic theories. Other tools, such as stock-flow diagrams (see Forrester, 1968), help overcome this limitation.

\section{Non-linear Relationships}

The majority of statistical tests used in social science and psychological research are based on assumptions of linearity. However, causal relationships among variables do not commonly exhibit linear relationships. One of the most common non-linear relationships is the Yerkes-Dodson performance curve (Yerkes \& Dodson, 1908) that shows a non-linear (and non-monotonic) relationship between arousal and performance. More recently, non-linear relationships have been hypothesized among variables such as stress and mood (Zohar, 1999); affect, symptoms, social interaction experience, and cognitive performance (Totterdell, Briner, Parkinson, \& Reynolds, 1996); various personality functions (Galatzer-Levy, 2004); and learning and hypermedia programs (Chen, 2002). Non-linear relationships need to be taken into consideration, as they can be a source of highly unpredictable behavioral patterns and are also the source for highly unpredictable processes. When they are disregarded, theories and models will have only loose correspondence with reality.

Unfortunately, CLDs are significantly limited in their ability to handle non-linear relationships. More specifically, they cannot communicate nonlinear relationships directly, and there is no way of discerning their impact on the behavior of a system. Moreover, when the linear relationships are also non-monotonic, they can also change the polarity of a feedback loop. This provides additional reasons for using other tools in the formulation and presentation of dynamic theories. Still, there are numerous applications of CLD and additional tools in research on urban minority families and communities.

\section{DYNAMIC MODELING AND URBAN MINORITY ADOLESCENT DEVELOPMENT}

Scholars (Burton, Allison, \& Obeidallah, 1995; Coll et al., 1996; Jarrett, 2003) have argued that life in urban environments contributes to the non-linear developmental trajectories often seen in African American youth. Owing to a number of relationships between urban communities of color and surrounding environments and to relationships within urban minority neighborhoods, dynamic modeling may be extremely helpful in explicating the non-linear developmental trajectories of youth living in these fragile and fragmented communities. 
Dynamic modeling can help increase our understanding of the pathways of youths of color as they traverse proximal and distal environments. When the relationship between the opportunity structure (e.g., business and employment opportunities) and urban African American communities are examined from a dynamic theory perspective, the non-linear trajectories of urban youths become clearer. For example, the near absence of an opportunity structure in many urban minority communities contributes to reduce employment opportunities at the community level, which causes many residents to travel several hours to places of employment. Hours invested in travel and work significantly impairs parents' ability to supervise their adolescent offspring. Unsupervised adolescents may participate in alternative market activities (e.g., drug trafficking) or other forms of antisocial behavior, which disrupt linear developmental competencies such as educational attainments, and lower levels of academic achievement at the community level discourage the growth of a business sector. Dynamic modeling provides a lens through which to examine important positive and negative feedback loops. It also provides a model on how these dynamic relationships change over time.

Furthermore, dynamic modeling can help understand the nontraditional developmental trajectories of urban youths of color by examining withingroup dynamics. For example, scholars (Jarrett, 2003; McLoyd, 1998) have argued that urban African American youths experience accelerated development, a process known as adultification or the downward extension of adult responsibilities to adolescents. However, there is little theoretical consideration to explain this phenomenon. When adultification is examined from a dynamic perspective, this phenomenon is seen as a natural adaptation to life in a resource-limited environment. Considering half of the households in urban African American neighborhoods are headed by a single female, it is pragmatic for adolescents to play an adult role. When such household patterns exist at the community level, the responses that youths receive from adults and peers in their community for adultifying is likely positive. As competencies are often determined at the community level (Ogbu, 1985), these youths probably demonstrate a high level of competence and high levels of efficacy within their communities. Increased efficacy and competence will in turn increase the adultification process, which will facilitate greater participation in the labor market by single mothers and increase the need for more adultified adolescents. Dynamic modeling allows the adultification process to be seen as the function of positive feedback loop.

\section{CONCLUSION AND FUTURE DIRECTIONS}

This article has highlighted the need to develop dynamic theories and models to explain dynamic social processes such as interpersonal and inter-group relationships. Tools and concepts from system dynamics have been intro- 
the pathonments. iness and nities are ctories of opportuduce emresidents in travel tolescent e market or, which linments, scourage ; through s. It also $r$ time. aditional 3 within98) have :d develxtension eoretical xamined laptation useholds : female, susehold ive from As com5), these ;h levels wetence : greater he need ification

- models rr-group $n$ intro-

duced as a way of guiding the field to meet this end. The goal was not to provide an exhaustive or highly technical review but instead to facilitate interested scholars to gain the basic building blocks of dynamic modeling for their own work. Engaging these tools and beginning this endeavor may also add additional insights into thought and action not previously manifested.

An additional advantage of dynamic systems modeling is its inherent ability to cope with contingency and emergence, which are two processes that influence the understanding of complex phenomena such as interpersonal and inter-group relations over time. Contingency and emergence can be thought of as counterpoints to reductionism in complex dynamic phenomena (Gould, 2003). The conduct of science in general and social psychological fields more specifically have typically relied perhaps too much on reductionism to explain complex phenomena by understanding the static architecture of the parts. Emergent properties are those that appear in dynamic systems as a result of non-linearity, and reductionism is inadequate for explaining these emergent or non-linear properties. Contingency refers to historical events, idiographic cases, and inherent particularism in a given system under study. These cases or events can occur by chance or accident. Therefore, linear principles are not as equipped to predict or explain these classes of phenomena.

A limitation of this study that is clearly recognized is how the research methodologies can be integrated into the theory development process. This limitation is, to an extent, purposefully constructed to ensure that the theory is driving the methodology rather than letting the methodology drive the theory, which is one of the explanations why there are so many static formulations. Some attention has been given to the utility of computer simulations as a viable way for developing and improving upon developing and testing dynamic models and ultimately improving upon the explanatory power of dynamic theories. The need for computer simulation in research is receiving increasing attention, and it is argued that it is an essential tool for examining dynamic processes (Forrester, 1968; Homer, 2001). Although the tools are still not advanced enough to model "living and breathing" systems of interpersonal and inter-group relations, the availability of tools and concepts to promote dynamic theory development is sufficient enough for students, and scientists in the field can become more active in developing dynamic theories and models.

\section{REFERENCES}

Burton, L. M., Allison, K. W., \& Obeidallah, D. (1995). Social context and adolescence: Perspectives on development among inner-city African American teens. In L. J. Crockett \& A. C. Crouter (Eds.), Patbways through adolescence.' (pp. 134-166). Hillsdale, NJ Lawrence Erlbaum Associates, Inc. 
Chen, S. (2002). A cognitive model for non-linear learning in hypermedia programmes. British Journal of Educational Technology, 33(4), 449-460.

Coll, C., Lamberty, G., Jenkins, R., McAdoo, H. P., Crnic, K., Wasik, B.H., et al. (1996, October). An integrative model for the study of developmental competencies in minority children. Child Development, 67(5), 1891-1914.

Dovidio, J. F., Gaertner, S. L., Esses, V. M., \& Brewer, M. B. (2003). Social conflict, harmony, and integration. In T. Millon \& M. Lerner (Eds.), Comprebensive bandbook of psycbology, Vol. 5: Personality and social psychology (pp. 485506). New York: Wiley.

Elder-Vass, D. (2007). Luhmann and emergentism: Competing paradigms for social systems theory? Philosopby of the Social Sciences, 37, 408-432.

Ford, A. (1999). Modeling the environment: An introduction to system dynamics models of environmental systems. Washington, DC: Island.

Forrester, J. W. (1968). Principles of systems. Waltham, MA: Pegasus.

Galatzer-Levy, R. M. (2004). Chaotic possibilities: Toward a new model of development. International Joumal of Psychoanalysis, 85(2), 419-441.

Gould, S. J. (2003). The bedgebog, the fox, and the magisters pox: Mending the gap between science and the bumanities. New York: Random House.

Hanneman, R. A., Collins, R., \& Mordt, G. (1995). Discovering theory dynamics by computer simulation: Experiments on state legitimacy and imperialist capitalism. Sociological Methodology, 25, 1-46.

High Performance Systems. (2004). Stella. Lebanon, NH: Author.

Hogg, M. A. (2006). Social identity theory. In P. J. Burke (Ed.), Contemporary social psychological theories (pp. 111-136). Palo Alto, CA: Stanford University Press.

Homer, J., \& Oliva, R. (2001). Maps and models in system dynamics: A response to Coyle. System Dynamics Review, 17(4), 347-355.

Jarrett, R. L. (2003). Worlds of development: The experiences of low-income, AfricanAmerican youth. Journal of Children \& Poverty, $9(2), 157-188$.

Kelly, J. R., \& McGrath, J. E. (1988). On time and method (vol. 13). Newbury Park, CA: Sage.

Matsumoto, D. (2007). Culture, context, and behavior. Journal of Personality, 75, 135.

McLoyd, V. (1998). Socioeconomic disadvantage and child development. American Psycbologist, 53, 185-204.

Ogbu, J. U. (1985). A cultural ecology of competence among inner-city blacks. In M. B. Spencer, G. K. Brookins, \& W. R. Allen (Eds.), Beginnings: The social and affective development of Black children (pp. 45-66). Hillsdale, NJ: Lawrence Erlbaum Associates.

Parkinson, B., Totterdell, P., Briner, R, B., \& Reynolds, S. (1996). Changing moods. New York, NY: Addison, Wesley, Longman.

Peck, S. C. (2007). TEMPEST in a gallimaufry: Applying multilevel systems theory to person-in-context research. Joumal of Personality, 75, 1127-1156.

Roberts, N., Andersen, D., Deal, R., Garet, M., \& Shaffer, W. (1983). Introduction to computer simulation. Reading, MA: Addison-Wesley.

Rudner, R. S. (1966). Pbilosophy of social science. Englewood Cliffs, NJ: Prentice-Hall.

Senge, P. M., Kleiner, A., Roberts, C., Ross, R. B., \& Smith, B. J. (1994). The fifth discipline fieldbook. New York: Currency and Doubleday. 
ıedia pro!. al. (1996, ipetencies

Il conflict, urebensive (pp. 485for social dynamics ¿developig the gap namics by sapitalism.

ary social ity Press. sponse to e, Africansury Park, ity, 75, 1American blacks. In iocial and Lawrence ig moods. itheory to duction to ntice-Hall, - The fifth
Thelen, E., \& Smith, L. B. (1998). Dynamic systems theories. In W. Damon \& R. M. Lerner (Eds.), Handbook of child psychology: vol. 1: Theoretical models of buman development (5th ed., pp. 563-634). New York: John Wiley \& Sons.

Tropp, L. R. (2007). Perceived discrimination and interracial contact: Predicting interracial closeness among black and white Americans. Social Psycbology Quarterly, $70,70-81$.

Vaughn, M. G. (2007). Biosocial dynamics: A transdisciplinary approach to violence. In M. Delisi \& P. J. Conis (Eds.), Violent offenders: Theory, research, public policy, \& practice (pp. 63-77). Sudbury, MA: Jones \& Bartlett.

Ventana Systems. (2004). Vensim. Harvard, MA: Author.

Walby, S. (2007). Complexity theory, systems theory, and multiple intersecting social inequalities. Pbilosopby of the Social Sciences, 37, 449-470.

Williams, K. D., \& Warburton, W. A. (2004). Ostracism: A form of indirect aggression that can result in aggression. International Review of Social Psycbology, 16, 101126.

Yerkes, R. M., \& Dodson, J. D. (1908). The relation of strength and stimulus to rapidity of habit-formation. Journal of Comparative Neurology and Psycbology, 18, 459-482.

Zohar, D. (1999). When things go wrong. The effect of daily work hassles on effort, exertion and negative mood. Journal of Occupational and Organizational Psycbology, 72, 265-283. 